\title{
Exploring the clinical utility of an electronic diary in fibromyalgia patients: A pilot study
}

\author{
M. Pilar Martínez ${ }^{1,2}$, Raquel García ${ }^{1}$, Ana I. Sánchez ${ }^{1,2}$, Germán Prados $^{3}$, Kawtar Benghazi $^{4}$, José \\ Luis Garrido ${ }^{4}$ and Elena Miró ${ }^{1,2}$ \\ ${ }^{I}$ Departamento de Personalidad, Evaluación y Tratamiento Psicológico, Universidad de Granada, Granada, España. \\ ${ }^{2}$ Centro de Investigación Mente, Cerebro y Comportamiento, Universidad de Granada, Granada, España. \\ ${ }^{3}$ Departamento de Enfermería, Universidad de Granada, Granada, España. \\ ${ }^{4}$ Departamento de Lenguajes y Sistemas Informáticos, Universidad de Granada, Granada, España.
}

\begin{abstract}
This study examines the clinical utility of an electronic diary (ED) in the monitoring of the clinical manifestations of fibromyalgia (FM), compared to traditional paper-pencil self-reports. Fourteen women with FM completed an interview, several questionnaires, and an ED for a week (several times a day) recording pain, fatigue, sleep, difficulty in thinking, emotional distress, difficulty in daily functioning, coping with the disease, and stress. There were no differences in symptoms throughout the different moments of the day. A sleep latency of 45.36 minutes and sleep duration of 6.25 hours was observed. Significant correlations were found between ED measures depending on the time of day, and between ED measures and questionnaires. The ED showed to be useful for the evaluation of FM symptomatology and could be a key component in psychological intervention programs.
\end{abstract}

Keywords: electronic diary; fibromyalgia; pain; sleep; emotional distress.

Explorando la utilidad clínica de un diario electrónico en pacientes con fibromialgia: Un estudio piloto

Resumen: Este estudio examina la utilidad de un diario electrónico (DE) en el seguimiento de las manifestaciones clínicas de la fibromialgia (FM) frente a los tradicionales autoinformes de lápiz y papel. Catorce mujeres con FM completaron una entrevista, varios cuestionarios y un DE durante una semana (varias veces al día) registrando dolor, fatiga, sueño, dificultad para pensar, malestar emocional, dificultad en el funcionamiento diario, afrontamiento de la enfermedad, y estrés. No hubo diferencias en los síntomas a lo largo de los momentos del día, observándose una latencia del sueño de 45,36 minutos y una duración del sueño de 6,25 horas. Se encontraron correlaciones significativas entre las medidas del DE dependiendo de la hora del día, y entre las medidas del DE y los cuestionarios. El DE demostró ser útil para la evaluación de la sintomatología de la FM y puede ser un componente clave en los programas de intervención psicológica.

Palabras clave: diario electrónico; fibromialgia; dolor; sueño; malestar emocional.

\section{Introduction}

Fibromyalgia (FM) is a clinical condition that causes widespread musculoskeletal pain and is accompanied by

Recibido: 16 de octubre de 2020; aceptado: 04 de octubre de 2021. Correspondence: Dra. M. Pilar Martínez. Departamento de Personalidad, Evaluación y Tratamiento Psicológico, Facultad de Psicología, Campus Universitario de Cartuja, 18071 Granada (España). E-mail: mnarvaez@ugr.es. other manifestations such as unrefreshing sleep, fatigue and cognitive deficits (Wolfe et al., 2010). Although the etiopathogenesis of FM is not yet sufficiently established, evidence suggests that it is a central sensitization disorder

Acknowledgment: This study is part of a broader research project financially supported by the Spanish Ministry of Economy and Competitiveness (ref. PSI2014-58379-P), Campus of International Excellence (CIE) BioTic Granada (ref. CEI2015-MP-V4), and a Research Initiation Grant (granted to R.G.) of the 2017 Research Plan of the University of Granada. 
(Woolf, 2011) in which there is an increased response to sensory inputs due to central nervous system hypersensitivity that leads to hyperalgesia and allodynia. Also, in FM the emotional disturbances affect the nervous, endocrine and immune systems which accounts for the homeostatic imbalance (dysautonomia and dysrhythmia) that finally explains the hormonal, circadian rhythm, and sleep disturbances, among other things (Álvaro \& Traver, 2010), taking into consideration the link between the imbalance of the autonomic nervous system and the main FM symptoms (Lledó et al., 2016).

Among the dysfunctions associated with FM, in recent years the important role of sleep disturbances has been emphasized (see review by $\mathrm{Wu}$ et al., 2017). FM patients complain of poor sleep quality, a greater number of awakenings and the presence of a fragmented sleep, with a greater proportion of phases N1 and N2 of NREM sleep and reduction of slow wave sleep (Díaz-Piedra et al., 2015). Nonrestorative sleep is related to higher levels of pain, emotional distress and lower self-efficacy and daily functioning (Andrade et al., 2020; Choy, 2015; Miró et al., 2011a), being a key aspect in the establishment of subgroups of FM patients (Martínez et al., 2021). Also, it has been shown that cognitive-behavioral therapy for insomnia (CBT-I) improves several of these aspects such as cognitive function (Miró et al., 2011b), daily functioning and psychological well-being (Martínez et al., 2014), and that the combined CBT for insomnia and pain (CBT-IP) produces positive changes in pain-related variables (Lami et al., 2018a). Taking all this into account, frequent sleep monitoring would have clinical value by contributing to the understanding of the impact of sleep on FM symptoms.

Given the implications of sleep in FM it is necessary to develop actions that improve the quality of life of patients and that generate sustainable costs for the health system. In this regard, the use of the Internet may be a way to reduce disbursements and facilitate access to therapy for patients with difficulties accessing by other means, including the use of mobile technology in the monitoring and maintenance of health (Walsh \& Groarke, 2019). Thus, the online evaluation via an electronic diary (ED) supposes a complement in the tandem of technology and health. EDs provide the therapist with immediate access to the recorded information and data processing by computer programs. Furthermore, electronic evaluation has been more favorable, compared to paper-pencil records, in terms of patient satisfaction (Sundararaman et al., 2017), a higher compliance rate, and a higher veracity of the data being collected (no omissions) because the participants must answer to reach the next screen (Ladores \& Bray, 2017).
In recent years, the use of electronic methods for painrelated data collection in musculoskeletal pain conditions, including FM, has increased (see review by Jibb et al., 2020). For example, García-Palacios et al. (2014) used an ED evaluating pain intensity, fatigue intensity and mood, and found more accurate and complete ratings of the ED compared to a paper diary, and utility of the ED for the evaluation of FM, even in patients with low familiarity with technology. However, there are almost no studies about the use of EDs to examine sleep in FM patients. Okifuji and Hare (2011) monitored sleep and other symptoms of FM (pain, fatigue, emotional distress, stiffness, self-efficacy and activity) with an ED (subjective method) compared to actigraphy (objective method) to evaluate the concordance between both methods. They found that patients with FM tended to misestimate the duration of their sleep in comparison to sleep duration recorded via actigraphy, and that this discrepancy was particularly large when their sleep was restless (objective method), they had difficulty falling asleep (subjective method), and when they felt tired at the time of reporting. Also, it was observed that FM symptoms were mostly related to subjective report of poor sleep but not to objective sleep data. Kothari et al. (2015) observed through an ED examining sleep quality, pain, positive affect, negative affect and activity interference, that positive affect and pain mediated the relationship between poor sleep quality and interference with daily activities in FM, underlining the usefulness of positive affect after a nonrefreshing night's sleep as a way of preserving daily functioning in FM. Via an ED Mun et al. (2020) identified morning pain catastrophizing and afternoon pain severity as sequential mediators of the relationship between previous night nonrestorative sleep and end-of-day activity interference in FM, suggesting the potential utility of interventions focused on improving both sleep quality and negative pain appraisal.

Although the previous findings on EDs are promising, the implementation of this type of devices to monitor the symptoms of FM, including sleep, is a little-explored field that requires further consolidation. The purpose of this study was to analyze the utility of an ED in the monitoring of sleep and other key clinical symptoms of FM (e. g., pain, fatigue, emotional distress, difficulty in daily functioning). The specific objectives were: (a) to explore the utility of an ED to find out about the possible fluctuation of symptoms of FM throughout the day (morning/afternoon/evening), and (b) to examine the convergent validity of the data recorded via the ED with respect to those collected by paper-pencil questionnaires. In connection with these objectives, the hypotheses raised were the following: 1) The clinical manifestations of FM (pain, fatigue, sleep, difficulty in thinking, emotional distress, difficulty in daily 
functioning, coping with the disease, and stress) evaluated via the ED will show significant differences depending on the time of day (morning, afternoon or evening); and 2) The clinical manifestations of FM evaluated via the ED will show significant correlations with the corresponding paperpencil questionnaires.

\section{Method}

\section{Participants and procedure}

Fourteen women with FM were recruited from Virgen de las Nieves University Hospital and AGRAFIM (an association of FM patients), both in Granada (Spain). Since the prevalence of FM in women is much higher than in men (Arout et al., 2018) only women were included. The eligibility criteria were: (a) being a woman aged between 18 and 67 years; (b) having met diagnostic criteria for FM (American College of Rheumatology, Wolfe et al., 2010) with no current severe co-morbid medical condition; (c) being stable regarding the intake of analgesics/antidepressant medication for at least 1 month before the study; (d) not having a history of psychotic and/or substance-related disorders or other severe psychological disorder; (e) not having sleep apnea, restless leg syndrome, myoclonia or circadian rhythm disorder; and (f) having an internet connection, email address and an electronic device (e.g., smartphone).

The potentially eligible sample consisted of 35 patients diagnosed with FM. After reviewing the eligibility criteria, 22 of them were selected and invited to attend an evaluation interview to obtain sociodemographic and clinical information on FM. Furthermore, they were given a battery of questionnaires to complete at home and were registered on the web platform from which the ED was managed with the indication that they should complete it three times a day (morning/afternoon/evening) during at least one week. All participants completed the interview and the questionnaires once, but 6 of them did not access the ED at any time (they alleged personal problems) and 2 completed it less than six times, so their data was excluded because it was considered insufficient for the analysis. The final sample consisted of 14 participants.

This research was approved by the Research Ethics Committee of the University of Granada. All patients participated in the study voluntarily, they were guaranteed the confidentiality of the data collected, and signed an informed consent document.

\section{Measures}

Electronic record of FM symptoms. An ED was developed and implemented in a web application accessible from smartphones through standard internet browsers, thus enabling the online recording of FM symptoms by patients, and subsequent monitoring by therapists (http://diarioclinico.everywaretech.es). It has been developed by using HTML5, Javascript and CSS technologies and Yii framework, a high-performance PHP context for developing Web 2.0 applications. The web application runs on an Apache server on Linux. It includes two distinct areas of work: the management backend for therapists and the frontend for patients. Users are registered anonymously being associated with a numeric identifier. The answers to the items are stored in a MySQL relational database, allowing therapists to download all answers in an Excel-compatible commaseparated data file. The access to the ED for patients was possible in three daily periods: morning (from 10:00 a.m. to 11:30 a.m.), afternoon (from 3:00 p.m. to 5:00 p.m.) and evening (from 7:30 p.m. to 11:30 p.m.). The ED consisted of 20 items, some of which could be answered on a Likert scale from 0 (not at all) to 10 (very much), others allowed patients to choose among different options and the rest were questions to be completed. The ED registered the following clinical areas: pain, fatigue, sleep, difficulty in thinking, emotional distress, difficulty in daily functioning, coping with the disease, and stress. Schedules and qualitative aspects explored in the ED (e.g., sources of stress, reason to wake up) were not included in the present study, so the data of 15 items was analyzed.

McGill Pain Questionnaire-Short Form (MPQ-SF; Melzack, 1987). It explores different dimensions of pain experience. For this study we selected the visual analogue scale that assesses pain intensity during the last week from 0 (no pain at all) to 10 (extreme pain). The MPQ-Spanishversion has adequate reliability (rank-scale correlation coefficients > .90) and validity (Lázaro et al., 2001).

Multidimensional Fatigue Inventory (MFI; Smets et al.,1995). It assesses several dimensions of fatigue via 20 items: general fatigue, physical fatigue, mental fatigue, reduced activity and decreased motivation. Items are assessed on a Likert scale from 1 (disagree) to 5 (totally agree). The general fatigue scale was used in this study. The MFI-Spanish-version presents acceptable reliability (intra-class correlation coefficients from .64 to .91) and construct validity in FM patients (MunguíaIzquierdo et al., 2012).

Pittsburgh Sleep Quality Index (PSQI; Buysse et al., 1989). It includes 19 items that measure several facets of sleep quality: subjective sleep quality, sleep latency, sleep duration, habitual sleep efficiency, sleep disturbances, use of sleeping medication, and daytime dysfunction. This study used the total score which ranges from 0 to 21 
(high scores represent worse sleep quality). Total scores $>5$ correspond to «bad sleepers» (Buysse et al., 1989). The PSQI-Spanish-version presents adequate reliability $(\alpha=.81)$, sensitivity and specificity (Royuela \& Macías, 1997).

Hospital Anxiety and Depression Scale (HADS; Zigmond \& Snaith, 1983). It explores the presence/ severity of symptoms of anxiety and depression via 14 items. Each item includes 4 response alternatives (from 0 to 3 ). The HADS-Spanish-version has adequate sensitivity and reliability $(\alpha=.80$ for the anxiety subscale and $\alpha=.85$ for the depression subscale). Cut-off points for the FM population (Cabrera et al., 2015) are the following: for the anxiety subscale $>12$ is considered significant anxiety, and $>16$ extreme anxiety, and for the depression scale $>10$ is considered moderate depression, and $>12$ severe depression.

Fibromyalgia Impact Questionnaire (FIQ; Burckhardt et al., 1991). It explores the FM impact on daily life using 10 items. Item 1 uses a Likert scale (ranges from 0 $=$ always to $3=$ never) to examine activities of daily living performed in the last week. Items 2 and 3 evaluate the number of days that patients felt well/unwell to work. The remaining items are based on a Likert scale from 0 to 10 which rate several symptoms. Total scores $\geq 59$ indicate severe impact (Bennett et al., 2009). The FIQSpanish-version has adequate reliability $(\alpha=.82)$ and validity (Rivera \& González, 2004).

Chronic Pain Self-Efficacy Scale (CPSS; Anderson et al.,1995). It explores self-efficacy expectations regarding pain management, coping with symptoms, and physical function via 19 items. Items are assessed on a Likert scale ranging from 0 (I believe totally incapable) to 10 ( $I$ believe totally capable). The CPSS-Spanish-version has excellent reliability $(\alpha=.91)$ and validity (MartínAragón et al., 1999).

\section{Data analysis}

All analyses were carried out via SPSS software (IBM SPSS Statistics for Windows, Version 20.0), and $95 \%$ confidence levels were used. The descriptive statistics of the categorical data are presented as frequencies and percentages and those of the continuous data as means and standard deviations. Because of the sample size, we decided to use nonparametric tests. Variations in ED measures as a function of time of day were examined by Friedman's two-way analysis of variance by ranks. To determine the convergent validity of the ED and the questionnaires, the relationships between the variables were examined through Spearman's rank correlation coefficients.

\section{Results}

\section{Sociodemographic and clinical data}

The mean age of the FM sample was 52.64 years $(S D=5.99)$. Most participants were married $(64.3 \%)$, $28.5 \%$ were separated/divorced, and $7.1 \%$ were unmarried. Regarding the level of education, $35.7 \%$ had professional instruction, $28.6 \%$ university studies, $21.4 \%$ basic education, and $7.1 \%$ secondary education. The largest group was employed (42.9\%), $28.6 \%$ were unemployed, $21.4 \%$ disabled, and $7.1 \%$ retired. The mean duration of FM diagnosis was 10 years $(S D=8.86)$. Most participants were taking antidepressant serotonin reuptake inhibitors and antipyretic analgesics (71.4\% each), 50\% were taking benzodiazepines, $35.7 \%$ non-steroidal anti-inflammatory drugs, and $14.3 \%$ tricyclic antidepressants.

\section{Descriptive data of the questionnaires}

Mean scores of the Pain-MPQ-SF and Sleep-PSQI (see Table 1) were equivalent to those obtained in previous studies with this population (e.g., Hita-Contreras et al., 2014). The values of the PSQI exceeded the cut-off point for poor sleep quality. The mean score of Fatigue-MFI was lower than in another study (Munguía-Izquierdo et al., 2012) in the same population. The mean score of Impact on daily functioning-FIQ was similar to another study in FM population showing disability (Esteve-Vives et al., 2007). Considering the HADS cut-off points, the mean score for the anxiety subscale was in the range of significant anxiety and for the depression subscale in the

Table 1. Descriptive data of questionnaires

\begin{tabular}{lc}
\hline & $M(S D)$ \\
\hline Pain-SF-MPQ & $7.00(1.79)$ \\
General fatigue-MFI & $4.53(0.58)$ \\
Sleep quality-PSQI & $13.75(3.49)$ \\
Anxiety-HADS & $11.86(4.53)$ \\
Depression-HADS & $9.69(3.30)$ \\
Impact on daily functioning-FIQ & $58.23(11.79)$ \\
Self-efficacy in pain-CPSS & $81.86(34.94)$ \\
\hline
\end{tabular}

Note. $M=$ mean; $S D=$ standard deviation; $\mathrm{MPQ}-\mathrm{SF}=\mathrm{McGill}$ Pain Questionnaire-Short Form; MFI = Multidimensional Fatigue Inventory; PSQI = Pittsburgh Sleep Quality Index; HADS = Hospital Anxiety and Depression Scale; FIQ = Fibromyalgia Impact Questionnaire; CPSS = Chronic Pain Self-efficacy Scale. 
range of moderate depression. The self-efficacy regarding pain-CPSS showed a better level of perceived ability to manage pain than in another study in this population (Lledó-Boyer et al., 2010).

\section{Descriptive data of the ED measures}

The mean frequency of ED registrations during the evaluation period was 18.42 times $(S D=11.59)$. The scores of the majority of the variables measured through the ED (see Table 2) had an average above 6 (on a scale from 0 to 10). The mean score of sleep latency was 45.36 minutes, with more than two awakenings per night and a duration of 18.75 minutes for each. The mean number of hours of sleep during the night was 6.25 hours, with a very low general assessment of restorative night-sleep, below the middle of the score range $(M=4.41)$. No differences were found for pain, fatigue, sleep, difficulty in thinking, emotional distress, difficulty in daily functioning, coping with the disease and stress depending on the different moments of the day.

Table 2. Descriptive data of electronic diary measures in different periods of the day

\begin{tabular}{lcccccccc}
\hline & \multicolumn{2}{c}{ Morning } & \multicolumn{2}{c}{ Afternoon } & \multicolumn{2}{c}{ Evening } & \multicolumn{2}{c}{ Total } \\
& $M$ & \multicolumn{1}{c}{$S D$} & \multicolumn{1}{c}{$M$} & \multicolumn{1}{c}{$S D$} & \multicolumn{1}{c}{$M$} & \multicolumn{1}{c}{$S D$} & \multicolumn{1}{c}{$M$} & \multicolumn{1}{c}{$S D$} \\
\hline Pain & 6.48 & 2.04 & 6.66 & 1.60 & 6.80 & 2.06 & 6.65 & 1.83 \\
Fatigue & 7.07 & 1.60 & 7.14 & 1.57 & 7.52 & 1.46 & 7.35 & 1.32 \\
Sleepiness & 5.60 & 1.77 & 6.27 & 1.88 & 5.45 & 2.28 & 5.91 & 1.71 \\
Difficulty in thinking & 5.85 & 1.60 & 6.49 & 1.36 & 5.95 & 1.58 & 6.13 & 1.31 \\
Emotional distress & 5.76 & 1.90 & 6.18 & 2.03 & 5.73 & 2.19 & 5.84 & 1.92 \\
Difficulty in daily functioning & 6.94 & 1.38 & 7.06 & 1.20 & 6.69 & 1.25 & 6.88 & 1.18 \\
Coping with the disease & 6.36 & 1.90 & 6.01 & 2.17 & 6.14 & 1.93 & 6.19 & 1.92 \\
Stress & 5.33 & 2.04 & 5.73 & 2.06 & 5.46 & 2.04 & 5.49 & 2.00 \\
Sleepiness at bedtime & 5.48 & 2.69 & 5.83 & 2.91 & 5.48 & 2.53 & 5.87 & 2.59 \\
Minutes in falling asleep & 47.15 & 30.05 & 45.52 & 31.01 & 41.20 & 22.99 & 45.36 & 27.95 \\
Number of awakenings & 2.47 & 1.77 & 2.39 & 1.33 & 2.68 & 1.71 & 2.51 & 1.47 \\
Minutes wakes up every time & 17.81 & 8.07 & 26.93 & 15.68 & 14.45 & 8.09 & 18.75 & 7.86 \\
Sleepiness on waking & 7.12 & 1.85 & 7.17 & 1.06 & 7.21 & 1.43 & 7.09 & 1.12 \\
Restful sleep & 4.20 & 1.62 & 4.51 & 1.73 & 4.09 & 1.91 & 4.41 & 1.25 \\
Sleeping hours & 6.46 & 1.29 & 6.22 & 0.91 & 6.48 & 1.15 & 6.25 & 1.05 \\
\hline
\end{tabular}

Note. $M=$ mean; $S D=$ standard deviation; Total = mean score of the morning, afternoon and evening.

\section{Correlational data between ED measures}

Several clinical aspects (pain, fatigue, restful sleep, emotional distress, difficulty in daily functioning, and coping with the disease), representative of physical/ psychological experience of FM (see Martínez et al., 2021) and consonant with the questionnaire items, were selected from the ED. The reliability of this set of variables was acceptable $(\alpha=.72)$ in all periods of the day.

Regarding these variables (see Table 3) significant correlations were found (related to morning-, afternoon- evening-, and total-mean scores) between pain and fatigue, pain and difficulty in daily functioning, and emotional distress and difficulty in daily functioning. No significant associations of coping with the disease and restful sleep were found with any other variable, except between each other in the afternoon. Fatigue showed a positive correlation with emotional distress in the morning and the evening. Pain and emotional distress also showed significant correlations in the morning and the evening. 
Table 3. Correlations between electronic diary measures in different periods of the day

\begin{tabular}{|c|c|c|c|c|c|c|}
\hline & Period of the day & Pain & Fatigue & Restful sleep & $\begin{array}{l}\text { Emotional } \\
\text { distress }\end{array}$ & $\begin{array}{l}\text { Difficulty in daily } \\
\text { functioning }\end{array}$ \\
\hline Fatigue & $\begin{array}{l}\text { Morning } \\
\text { Afternoon } \\
\text { Evening } \\
\text { Total }\end{array}$ & $\begin{array}{l}.89 * * \\
.79 * * \\
.91 * * \\
.91 * *\end{array}$ & & & & \\
\hline Restful sleep & $\begin{array}{l}\text { Morning } \\
\text { Afternoon } \\
\text { Evening } \\
\text { Total }\end{array}$ & $\begin{array}{r}-.33 \\
.44 \\
-.21 \\
-.09\end{array}$ & $\begin{array}{r}-.26 \\
.40 \\
-.15 \\
-.10\end{array}$ & & & \\
\hline Emotional distress & $\begin{array}{l}\text { Morning } \\
\text { Afternoon } \\
\text { Evening } \\
\text { Total }\end{array}$ & $\begin{array}{l}.79 * * \\
.25 \\
.68^{* *} \\
.60 *\end{array}$ & $\begin{array}{l}.79 * * \\
-.08 \\
.69 * * \\
.58 *\end{array}$ & $\begin{array}{r}.01 \\
.32 \\
-.38 \\
.22\end{array}$ & & \\
\hline Difficulty in daily functioning & $\begin{array}{l}\text { Morning } \\
\text { Afternoon } \\
\text { Evening } \\
\text { Total }\end{array}$ & $\begin{array}{l}.61^{*} \\
.54^{*} \\
.64^{*} \\
.66^{* *}\end{array}$ & $\begin{array}{l}.54 \\
.26 \\
.68 * * \\
.68 * *\end{array}$ & $\begin{array}{l}-.40 \\
-.04 \\
-.05 \\
-.33\end{array}$ & $\begin{array}{l}.58^{*} \\
.68^{* *} \\
.71^{* *} \\
.65^{*}\end{array}$ & \\
\hline Coping with the disease & $\begin{array}{l}\text { Morning } \\
\text { Afternoon } \\
\text { Evening } \\
\text { Total }\end{array}$ & $\begin{array}{r}.26 \\
.21 \\
-.01 \\
.25\end{array}$ & $\begin{array}{l}.23 \\
.14 \\
.15 \\
.24\end{array}$ & $\begin{array}{l}.41 \\
.78 * * \\
.15 \\
.42\end{array}$ & $\begin{array}{r}.40 \\
.07 \\
-.13 \\
-.03\end{array}$ & $\begin{array}{r}-.15 \\
-.34 \\
.01 \\
-.15\end{array}$ \\
\hline
\end{tabular}

Note. Total $=$ mean score of the morning, afternoon and evening. ${ }^{*} p<.05 . * * p<.01$.

\section{Correlational data between questionnaires and ED measures}

Considering the total scores, significant correlations were observed between pain measured through the MPQ-SF and pain and fatigue assessed through the ED.
Also, the emotional distress measured by the ED correlated positively with the anxiety-HADS and the impact on daily functioning-FIQ (see Table 4). No significant correlations were observed between restful sleep, difficulty in daily functioning and coping with the disease examined via the ED and the questionnaires.

Table 4. Correlations between questionnaires and electronic diary measures

\begin{tabular}{|c|c|c|c|c|c|c|}
\hline & Pain & Fatigue & Restful sleep & $\begin{array}{c}\text { Emotional } \\
\text { distress }\end{array}$ & $\begin{array}{l}\text { Difficulty in } \\
\text { daily function- } \\
\text { ing }\end{array}$ & $\begin{array}{l}\text { Coping with } \\
\text { the disease }\end{array}$ \\
\hline Pain-SF-MPQ & $.72 * *$ & $.60 *$ & .01 & .26 & .45 & -.01 \\
\hline General fatigue-MFI & .03 & -.13 & -.03 & .25 & .10 & -.51 \\
\hline Sleep quality-PSQI & .01 & .05 & -.29 & .27 & .27 & -.32 \\
\hline Anxiety-HADS & .35 & .18 & .40 & $.55^{*}$ & .48 & .16 \\
\hline Depression-HADS & -.03 & -.13 & .37 & .47 & .34 & -.06 \\
\hline Impact on daily functioning-FIQ & .45 & .51 & .43 & $.59 *$ & .28 & -.01 \\
\hline Self-efficacy in pain-CPSS & .04 & .14 & -.41 & -.25 & -.24 & .19 \\
\hline
\end{tabular}

Note. MPQ-SF = McGill Pain Questionnaire-Short Form; MFI = Multidimensional Fatigue Inventory; PSQI = Pittsburgh Sleep Quality Index; HADS = Hospital Anxiety and Depression Scale; FIQ = Fibromyalgia Impact Questionnaire; CPSS = Chronic Pain Self-efficacy Scale. $* p<.05 . * *<.01$. 


\section{Discussion}

This study aimed to analyze the utility of EDs as part of the psychological assessment protocol for FM. The first objective was to explore the possibilities offered by EDs to monitor sleep and fluctuation of FM symptoms throughout the day. The sleep characteristics observed in the sample are congruent with the definition of insomnia (American Psychiatric Association, 2013), and are in line with those reported in the review by Díaz-Piedra et al. (2015), Prados and Miró (2012), and Wu et al. (2017), who found a typically insufficient and poor sleep quality, a large number of awakenings and not very efficient sleep in FM patients. Results for pain, fatigue, difficulty in thinking, emotional distress, difficulty in functioning, coping with the disease and stress showed moderate to high intensity levels.

Sleep dysfunctions play an important role in the pathophysiology of FM. Sleep deprivation and reduced slow-wave sleep interfere with the activity of the descending pathways of pain inhibition and disturb the functioning of the hypothalamic-pituitary-adrenal axis responsible for regulating the response to stress, resulting in an intensification of the sensitivity to painful stimuli and other non-painful sensations and making it difficult to cope with pain (Choy, 2015). Several studies have documented these links (see review by Prados \& Miró, 2012). For example, Andrade et al. (2020) reported a high prevalence of sleep difficulties in FM and the relationship of these sleep alterations with FM symptoms such as pain. Although the links between the clinical manifestations of FM are complex and multidirectional, it can be expected that the more pain/fatigue are present the more stress, emotional distress, difficulty in thinking and coping with the disease will be experienced, affecting to a greater or lesser extent the daily functioning. The ED can be an excellent tool to explore these relationships.

Regarding the fluctuation of the symptomatology along the morning, afternoon and evening time slots, no significant differences were found in the examined parameters. Hypothesis 1 was not confirmed. In contrast, Iacob et al. (2016) observed a significant effect of the time of day on pain, showing worse pain in the evening. Cambras et al. (2018) found an alteration of the circadian rhythm in chronic fatigue and myalgic encephalomyelitis patients compared to healthy people. They observed that circadian rhythm (activity and skin temperature) correlated negatively with clinical features (fatigue, sleep disturbances, anxiety, depression and autonomic symptoms) and correlated positively with health-related quality of life. However, the presence of circadian oscillations in FM symptoms has been little investigated.
The absence of variations in the measures of the present study as a function of the time of day is striking because it is known that psychophysiological/behavioral parameters show rhythmic oscillations of circadian type (Schibler, 2017). It is possible that with a larger sample of repeated measurements per participant, these variations would be detected. On the other hand, in the specific case of chronic pain, it should be considered that patients tend to score high in pain catastrophizing (Lami et al., 2018b), which may be at the core of the extreme negative view of symptoms that FM patients show and may have the effect of homogenizing the variations depending on the time of day. This aspect should to be analyzed by future research.

Nevertheless, changes were observed depending on the time of day with respect to the way in which certain measures were related to each other. In this way, pain and fatigue were associated with emotional distress at the beginning and the end of the day, being logical that these moments of the day with worse physical discomfort were associated with more emotional distress. Only in the evening fatigue was associated with greater difficulty in daily functioning, which may be because as the day progresses the ability to counteract the effect of fatigue decreases. In the afternoon, the better the assessment of sleep was, the better the coping with the disease. The contribution of sleep to the key symptoms of FM has been shown in different studies, in fact, worse sleep quality is associated with less self-efficacy being both variables significant mediators of the relationship between pain and emotional distress (Miró et al., 2011a). At any time of the day, a greater degree of pain is accompanied by higher levels of fatigue and difficulties in daily functioning, and these difficulties in daily functioning are associated to emotional distress. Similar results were found in the study by Kothari et al. (2015), where the perception of a poor sleep quality in the morning predicted high levels of pain at the end of the morning, the latter being related to interferences with the activity at the end of the day.

The second objective of the study was to explore the convergent validity of the data recorded by the ED with respect to the data collected through questionnaires. The results support the concordance of the ED regarding the measures of pain and emotional distress with the MPQ-SF and the HADS, respectively, but not concerning other parameters. Hypothesis 2 was partially confirmed. Possibly some differences related to the content of the ED items compared to the questionnaires may explain these findings. It should be considered that the questionnaires include multidimensional aspects of the variables that are not contemplated in the simple estimates of the respective 
variables in the ED. In addition, the different time criteria for assessing the clinical contents (current time in the ED vs. last week/month in the questionnaires) can modulate the estimation of the experience and make it difficult to converge the data of the different procedures, being probably more precise the data corresponding to the ED. Additionally, the lack of convergence between the ED and some questionnaires may also be due to the fact that participants just grew weary of answering questionnaires, and stopped giving valid and thoughtful responses. It should be noted that FM patients often experience mental fatigue and have difficulty concentrating, which can be a handicap in completing a battery of questionnaires. Nevertheless, in general, the results of the ED used in this study is in line with recent reviews on the integration of mobile health technology in chronic pain therapy that conclude that electronic assessment programs show robust reliability and validity (Sundararaman et al., 2017).

There are several limitations of the current study. First, the small sample size may limit the statistical power of the results obtained. However, the significant findings found in this study suggest the relevance of the phenomenon and the worthy continuation with a larger sample. Second, the participants were women, which prevent the generalization of the findings to the male population. Third, it would have been of interest to include an FM control group that would have filled out a daily record in traditional format to achieve a better estimate of the scope of the ED. Finally, the subjective measures of sleep are very useful, but they do not always match with the results of objective measures such as actigraphy (Okifuji \& Hare, 2011), with greater sleep disturbances in FM being reported via subjective methods compared to objective methods (Wu et al., 2017).

The use of EDs in FM provides advantages such as the communication of symptoms between the patient and health professionals, or the remote processing of the data collected by the ED. This may be of help in alleviating the burden of consultations in the public health system by allowing for the online monitoring of the disease in those cases in which this methodology is considered appropriate. Also, it would be beneficial for those patients who have difficulties to physically move to the consultation because of the discomfort imposed by the symptoms. Undoubtedly, this would have a favourable impact on the healthcare system, with a reduction of costs and an improvement in professional performance.

Future research should determine users' degree of confidence related to online registration, examine the consistency between the data collected via the ED and the data collected via objective measures, and explore the viability of EDs as an integrated part of treatments administered via web platforms. Also, repeated ED measures during treatment may be useful to identify the mechanisms through which the therapeutic change occurs.

In short, EDs are useful in the monitoring of FM symptoms. EDs can contribute to the improvement of clinical practice and the reduction of costs by using technology, in order to offer quality and sustainable psychological care adapted to the technological world that surrounds us.

\section{Conflicts of interest}

The authors have no conflicts of interest to declare.

\section{References}

Álvaro, T., y Traver, F. (2010). Una visión psiconeuroinmunológica de la fibromialgia [A psychoneuroimmunological view of fibromyalgia]. Revista de Psicopatología y Psicología Clínica, 15(3), 149-163. https://doi.org/10.5944/rppc.vol.15.num.3.2.

American Psychiatric Association (2013). Diagnostic and statistical manual of mental disorders (5th ed.). American Psychiatric Association.

Anderson, K. O., Dowds, B. N., Pelletz, R. E., Edwards, W. T., \& Peeters-Asdourian, C. (1995). Development and initial validation of a scale to measure self-efficacy beliefs in patients with chronic pain. Pain, 63(1), 77-84. https://doi. org/10.1016/0304-3959(95)00021-J.

Andrade, A., Vilarino, G. T., Sieczkowska, S. M., Coimbra, D. R., Bevilacqua, G. G., \& Steffens, R. D. (2020). The relationship between sleep quality and fibromyalgia symptoms. Journal of Health Psychology, 25(9), 1176-1186. https://doi. org/10.1177/1359105317751615.

Arout, C. A., Sofuoglu, M., Bastian, L. A., \& Rosenheck, R. A. (2018). Gender differences in the prevalence of fibromyalgia and in concomitant medical and psychiatric disorders: A national veterans health administration study. Journal of Women's Health, 27(8), 1035-1044. https://doi.org/10.1089/jwh.2017.6622.

Bennett, B. M., Bushmakin, A. G., Cappelleri, J. C., Zlateva, G., \& Sadosky, A. B. (2009). Minimal clinically important difference in the Fibromyalgia Impact Questionnaire. The Journal of Rheumatology, 36(6), 1304-1311. https://doi. org/10.3899/jrheum.081090.

Burckhardt, C. S., Clark, S. R., \& Bennett, R. M. (1991). The Fibromyalgia Impact Questionnaire: Developed and validation. Journal of Rheumatology, 18(5), 728-733.

Buysse, D. J., Reynolds, C. F., Monk, T. H., Berman, S. R., \& Kupfer, D. J. (1989). The Pittsburgh Sleep Quality Index: A new instrument for psychiatric practice and research. Psychiatry Research, 28(2), 193-213. https://doi.org/10.1016/01651781(89)90047-4.

Cabrera, V., Martín-Aragón, M., Terol, M. C., Núñez, R., y Pastor, M. A. (2015). La Escala de Ansiedad y Depresión Hospitalaria (HAD) en fibromialgia: análisis de sensibilidad y especificidad [The Hospital Anxiety and Depression Scale (HAD) in fibromyalgia: Analysis of sensitivity and specificity]. Terapia 
Psicológica, 33(3), 181-193. https://doi.org/10.4067/S071848082015000300003.

Cambras, T., Castro-Marrero, J., Cleofé, M., Díez-Noguera, A., \& Alegre, A. (2018). Circadian rhythm abnormalities and autonomic dysfunction in patients with chronic fatigue syndrome/myalgic encephalomyelitis. PLos ONE, 13(6), e0198106. https://doi.org/10.1371/journal.pone.0198106.

Choy, E. H. S. (2015). The role of sleep in pain and fibromyalgia. Nature Reviews Rheumatology, 11(9), 513-520. https://doi. org/10.1038/nrrheum.2015.56

Díaz-Piedra, C., Di Stasi, L. L., Baldwin, C. M., Buela-Casal, G., \& Catena, A. (2015). Sleep disturbances of adult women suffering from fibromyalgia: A systematic review of observational studies. Sleep Medicine Review, 21, 86-99. https://doi.org/10.1016/j.smrv.2014.09.001.

Esteve-Vives, J., Rivera-Redondo, J., Salvat-Salvat, M. I., de Gracia-Blanco, M., y Alegre de Miguel, C. (2007). Propuesta de versión de consenso del Fibromyalgia Impact Questionnaire (FIQ) para la población española. [Proposal for a consensus version of the Fibromyalgia Impact Questionnaire (FIQ) for the Spanish population]. Reumatología Clínica, 3(1), 21-24. https://doi.org/10.1016/S1699-258X(07)73594-5.

García-Palacios, A., Herrero, R., Belmonte, M. A., Castilla, D., Guixeres, J., Molinari, G., Baños, R. M., \& Botella, C. (2014). Ecological momentary assessment for chronic pain in fibromyalgia using a smartphone: A randomized crossover study. European Journal of Pain, 18(6), 862-872. https://doi. org/10.1002/j.1532-2149.2013.00425.x.

Hita-Contreras, F., Martínez-López, E., Latorre-Román, P. A., Garrido, F., Santos, M., \& Martínez-Amat, A. (2014). Reliability and validity of the Spanish version of the Pittsburgh Sleep Quality Index (PSQI) in patients with fibromyalgia. Rheumatology International, 34(7), 929-936. https://doi. org/10.1007/s00296-014-2960-z.

Iacob, E., Donaldson, G., Neikrug, A., Nakamura, Y., \& Okifuji, A. (2016). Self-report ecological momentary assessment in patients with fibromyalgia to examine temporal relationships between pain with mood, fatigue, and sleep. The Journal of Pain, 17(4), S6. https://doi.org/10.1016/j.jpain.2016.01.024.

Jibb, L. A., Khan, J. S., Seth, P., Lalloo, C., Mulrooney, L., Nicholson, K., Nowak, D. A., Kaur, H., Chee-A-Tow, A., Foster, J., \& Stinson, J. N. (2020). Electronic data capture versus conventional data collection methods in clinical pain studies: Systematic review and meta-analysis. Journal of Medical Internet Research, 22(6), e16480. https://doi. org/10.2196/16480.

Kothari, D. J., Davis, M. C., Yeung, E. W., \& Tennen, H. A. (2015). Positive affect and pain: Mediators of the within-day relation linking sleep quality to activity interference in fibromyalgia. Pain, 156(3), 540-546. https://doi.org/10.1097/01.j.pain.0000460324.18138.0a

Ladores, S., \& Bray, L.A. (2017). Electronic diaries in healthcare: A review of literature. Journal of Nursing Practice Applications \& Reviews of Research, 7(2), 13-21. https://doi. org/10.13178/jnparr.2017.0702.0705.

Lami, M. J., Martínez, M. P., Miró, E., Sánchez, A. I., \& Guzmán, M. A. (2018b). Catastrophizing, acceptance, and coping as mediators between pain and emotional distress and disability in fibromyalgia. Journal of Clinical Psychology in Medical Settings, 25(1), 80-92. https://doi.org/10.1007/s10880-018-9543-1.
Lami, M. J., Martínez, M. P., Miró, E., Sánchez, A. I., Prados, G., Cáliz, R., \& Vlaeyen, J.W.S. (2018a). Efficacy of combined cognitive-behavioral therapy for insomnia and pain in fibromyalgia patients: A randomized controlled trial. Cognitive Therapy and Research, 42, 63-79. https://doi.org/10.1007/ s10608-017-9875-4.

Lázaro, C., Caseras, X., Whizar-Lugo, V. M., Wenk, R., Baldioceda, F., Bernal, R., Ovalle, A., Torrubia, R., \& Baños, J. E. (2001). Psychometric properties of a Spanish version of the McGill Pain Questionnaire in several Spanish-speaking countries. The Clinical Journal of Pain, 17(4), 365-374.

Lledó, A., Fernández-Díez, E., Pastor, M. A., López-Roig, S., Ibáñez Ballesteros, J., \& Sorinas Nerín, J. (2016). Funcionamiento del sistema nervioso autónomo y estado de salud en la fibromialgia [Functioning of the autonomic nervous system and health status in fibromyalgia]. Revista de Psicopatología y Psicología Clínica, 21(2), 119-128. https://doi.org/10.5944/rppc.vol.21. num.2.2016.15499.

Lledó-Boyer, A., Pastor-Mira, M. A., Pons-Calatayud, N., LópezRoig, S., Rodríguez-Marín, J., \& Bruehl, S. (2010). Control beliefs, coping and emotions: Exploring relationships to explain fibromyalgia health outcomes. International Journal of Clinical and Health Psychology, 10(3), 459-476.

Martín-Aragón, M., Pastor, M. A., Rodríguez-Marín, J., March, M. J., Lledó, A., López-Roig, S., y Terol, M. C. (1999). Percepción de autoeficacia en dolor crónico. Adaptación y validación de la Chronic Pain Self-efficacy Scale. [Perception of self-efficacy in chronic pain. Adaptation and validation of the Chronic Pain Self-efficacy Scale]. Revista de Psicología de la Salud, 11(1-2), 53-75. https://doi.org/10.21134/pssa.v11i1.1177.

Martínez, M. P., Miró, E., Sánchez, A. I., Díaz-Piedra, C., Cáliz, R., Vlaeyen, J. W. S., \& Buela-Casal, G. (2014). Cognitivebehavioral therapy for insomnia and sleep hygiene in fibromyalgia: A randomized controlled trial. Journal of Behavioral Medicine, 37(4), 683-697. https://doi.org/10.1007/ s10865-013-9520-y.

Martínez, M. P., Sánchez, A. I., Prados, G., Lami, M. J., Villar, B., \& Miró, E. (2021). Fibromyalgia as a heterogeneous condition: Subgroups of patients based on physical symptoms and cognitive-affective variables related to pain. The Spanish Journal of Psychology, 24, e33. https://doi.org/10.1017/SJP.2021.30.

Melzack, R. (1987). The short-form McGill Pain Questionnaire. Pain, 30(2), 191-197.

Miró, E., Lupiáñez, J., Martínez, M. P., Sánchez, A. I., DíazPiedra, C., Guzmán, M. A., \& Buela-Casal, G. (2011b). Cognitive-behavioral therapy for insomnia improves attentional function in fibromyalgia syndrome: A pilot, randomized controlled trial. Journal of Health Psychology, 16(5), 770-782. https://doi.org/10.1177/1359105310390544.

Miró, E., Martínez, M. P., Sánchez, A. I., Prados, G., \& Medina, A. (2011a). When is pain related to emotional distress and daily functioning in fibromyalgia syndrome? The mediating roles of self-efficacy and sleep quality. British Journal of Health Psychology, 16(4), 799-814. https://doi.org/10.1111/ j.2044-8287.2011.02016.x.

Mun, C. J., Davis, M. C., Campbell, C. M., Finan, P. H., \& Tennen, H. (2020). Linking nonrestorative sleep and activity interference through pain catastrophizing and pain severity: An intraday process model among individuals with fibromyalgia. The 
Journal of Pain, 21(5-6), 546-556. https://doi.org/10.1016/j. jpain.2019.09.001.

Munguía-Izquierdo, D., Segura-Jiménez, V., Camiletti-Moirón, D., Pulido-Martos, M., Álvarez-Gallardo, I. C., Romero, A., Aparicio, V. A., Carbonell-Baeza, A., \& Delgado-Fernández, M. (2012). Multidimensional Fatigue Inventory: Spanish adaptation and psychometric properties for fibromyalgia patients. The Al-Ándalus study. Clinical and Experimental Rheumatology, 30(Suppl. 74), 94-102.

Okifuji, A., \& Hare, B. D. (2011). Nightly analyses of subjective and objective (actigraphy) measures of sleep in fibromyalgia syndrome: What accounts for the discrepancy?. The Clinical Journal of Pain, 27(4), 289-296. https://doi.org/10.1097/ AJP.0b013e31820485db.

Prados, G., y Miró, E. (2012). Fibromialgia y sueño: una revisión [Fibromyalgia and sleep: A review]. Revista de Neurología, 54(4), 227-240.

Rivera, J. \& González, T. (2004). The Fibromyalgia Impact Questionnaire: A validated Spanish version to assess the health status in women with fibromyalgia. Clinical and Experimental Rheumatology, 22(5), 554-560.

Royuela, A., y Macías, J. (1997). Propiedades clinimétricas de la versión castellana del cuestionario de Pittsburg [Clinimetric properties of the Spanish version of the Pittsburg questionnaire]. Vigilia-Sueño, 9(2), 81-94.

Schibler, U. (2017). Interaction between central and peripheral clock in mammals. In K. Vinod (Ed.), Biological timekeeping: Clocks, rhythms and behaviour (pp. 337-363). Springer.
Smets, E. M., Garssen, B., Bonke, B., \& De Haes, J. C. (1995). The Multidimensional Fatigue Inventory (MFI) psychometric qualities of an instrument to assess fatigue. Journal of Psychosomatic Research, 39(3), 315-325. https://doi. org/10.1016/0022-3999(94)00125-O.

Sundararaman, L. V., Edwards, R. R., Ross, E. L., \& Jamison, R. N. (2017). Integration of mobile health technology in the treatment of chronic pain: A critical review. Regional Anesthesia and Pain Medicine, 42(4), 488-498. https://doi. org/10.1097/AAP.0000000000000621.

Walsh, J. C. \& Groarke, J. M. (2019). Integrating behavioral science with mobile (mhealth) technology to optimize health change interventions. European Psychologist, 24(1), 38-48. https://doi.org/10.1027/1016-9040/a000351.

Wolfe, F., Clauw, D. J., Fitzcharles, M. A., Goldenberg, D. L., Katz, R. S., Mease, P., Russell, A.S., Russell, I. J., Winfield, J. B., \& Yunus, M. B. (2010). The American College of Rheumatology preliminary diagnostic criteria for fibromyalgia and measurement of symptom severity. Arthritis Care Research, 62(5), 600-610. https://doi.org/10.1002/acr.20140.

Woolf, C. J. (2011). Central sensitization: Implications for the diagnosis and treatment of pain. Pain, 152 (3 Suppl.), S2-S15. https://doi.org/10.1016/j.pain.2010.09.030.

Wu, Y. L., Chang, L. Y., Lee, H. C., Fang, S. Ch., \& Tsai, P. S. (2017). Sleep disturbances in fibromyalgia: A meta-analysis of case-control studies. Journal of Psychosomatic Research, 96, 89-97. https://doi.org/10.1016/j.jpsychores.2017.03.011.

Zigmond, A. S., \& Snaith, R. P. (1983). The Hospital Anxiety and Depression Scale. Acta Psychiatrica Scandinavica, 67(6), 361-370. 